\title{
MEASLES IN LARUT, MATANG AND SELAMA: ANALYSIS AND EVALUATION OF CLINICAL CASE DEFINITIONS FOR 2015-2019
}

\author{
Asraf Ahmad Qamruddin ${ }^{1}$, Afiq Malek ${ }^{1}$, Asnita Rozali ${ }^{1}$ and Norsihimah Wahid ${ }^{1}$ \\ ${ }^{1}$ Larut Matang and Selama District Health Office, Ministry of Health, Perak, Malaysia.
}

Corresponding author: Asraf Ahmad Qamruddin

Email: dr.asraf@moh.gov.my

\begin{abstract}
An accurate system of identifying measles cases is critical for the measles surveillance system. The objectives were: 1) To determine the incidence rate of measles in Larut, Matang and Selama district in Perak from 2015 to 2019 2) To evaluate the measles clinical case definition by comparing the performance of the measles clinical case definition in predicting laboratory-confirmed measles case. A cross-sectional analysis was carried out looking at all suspected and laboratory-confirmed measles cases in Larut, Matang and Selama District registered on the online measles surveillance reporting system between 2015 to 2019. The sensitivity, specificity, positive predictive value and negative predictive value of the clinical case definition as confirmed by the laboratory result were calculated. The incidence rate for suspected measles showed an increasing trend from 3.96 per 100,000 population in 2015 to 28.82 per 100,000 population in 2019. For laboratory-confirmed measles cases, the incidence rate showed more variation with an increase to 36.11 per million population in 2017 from 5.67 per million population in 2015. The incidence rate later decreased to 10.99 per million population in 2018 and increased again to 24.47 per million population in 2019. The sensitivity of the clinical case definition in confirming measles was $86.67 \%$ (95\% Cl: $69.28 \%$, 96.24\%), specificity $47.52 \%$ (95\% Cl: $41.56 \%$, $53.52 \%)$, positive predictive value $14.95 \%$ (95\% Cl $12.81 \%, 17.36 \%)$ and negative predictive value $97.10 \%(93.03 \%$, 98.83\%). Measles incidence is increasing in trend. The clinical case definition is an effective tool to rule out measles in cases that failed to meet the criteria due to the high negative predictive value of the definition. However, for cases that meet the clinical case definition, laboratory confirmation or epidemiological link to a confirmed case is needed.
\end{abstract}

Keywords: measles, epidemiology, sensitivity, specificity, positive predictive value, negative predictive value.

\section{INTRODUCTION}

Measles is a highly contagious disease. The disease is caused by a single-stranded RNA virus of the genes Morbilivirus from the paramyxovirus family ${ }^{1}$. The virus is transmitted from the nose, mouth or throat of an infected person to another person via droplets ${ }^{2}$. The symptoms usually appear within 10 to 12 days after exposure and included high fever with cough, coryza and conjunctivitis ${ }^{3}$. Several days later, this is followed by a maculopapular rash which normally starts from the face and upper neck and gradually spreading downwards.

Measles infection is associated with significant morbidity and mortality, especially in the paediatric age group. Worldwide, in the 1980s, measles was believed to be responsible for around 1 to 2 million death per year, mostly in developing countries, mainly for children aged 6 years and below $^{4}$. The estimated case fatality rate for measles is believed to be between $0.05 \%$ to $6 \%$, worse in situations of conflicts $^{5}$. $18 \%$ of all reported cases required hospitalisation with $8 \%$, $6 \%$ and $0.1 \%$ suffered complications such as diarrhoea, pneumonia and encephalitis respectively. Even for the survivors of the measles, it is not without their long-term complications. As many as one in 10000 may eventually develop subacute sclerosing panencephalitis (SSPE) within 10 to 20 years $^{6}$.
SSPE leads to neurological complications such as memory loss, unsteady death and even death in late adolescent ${ }^{7}$.

The development of the measles vaccine and it's routine inclusion into childhood immunisation have greatly altered the mortality and morbidity associated with measles. There was a $75 \%$ reduction of death from measles-related from 733000 in the year 2000 to 146000 in the year 2013. . In Malaysia, from 1982 until 2002, a single dose of measles-containing-vaccine (MCV) was given to children at 9 months of age as part of the Ministry of Health Expanded Program of Immunization'. As a result, the incidence rate of measles drops from 65.2 cases per 100,000 population in 1982 to between 1.51 and 5.87 cases per 100,000 population between 1989 to $1998^{10}$. Subsequently, from 2002, as part of the measles elimination strategy, the Malaysian Ministry of Health introduced double dose measles-mumpsrubella (MMR) vaccine at 12 months and 7 years old $^{10}$.

World Health Organization (WHO) had set a regional target for the Western Pacific Region which Malaysia is part of to eliminate measles by the year $2012^{11}$. Malaysia initially showing success with the incidence of measles reduced to 2.27 cases per 100,000 population in 2006 and maintained at a similar level until $2010^{10}$. However, in 2011 and 2012 the incidence 
increased with outbreaks reported in few states in Malaysia. This is believed to be caused by the degree of population under-vaccination ${ }^{12}$. The reported incidence per $1,000,000$ population increased from 6.6 cases in 2013 to 43.2 in 2015, 52.3 in 2017 and 59.6 in 2018 ${ }^{13}$. In 2016, Malaysia followed WHO recommendation and changed the MCV vaccination schedule to MCV1 at 9 months followed by MCV2 at 12 months ${ }^{14}$.

Measles surveillance is an essential part of the Measles Elimination Programme. Measles surveillance in Malaysia is based on a case classification system. The clinical case definition used for suspected measles is; any person with fever and maculopapular (i.e non-vesicular) rash and one of the following: cough or coryza or conjunctivitis $^{15,16}$. Studies have shown that when measles incidence is high, the clinical case definition performs reasonably well in identifying measles cases ${ }^{17}$. However, the accuracy of the clinical case definition in detecting measles cases is affected as measles elimination progresses and as the incidence rate changes ${ }^{18}$. The objectives of this study were to analyse the incidence rate of measles in Larut, Matang and Selama district in Perak from 2015 to 2019 and to evaluate the measles clinical case definition by comparing the performance of the measles clinical case definition in predicting laboratory-confirmed measles case.

\section{METHODS}

We conducted a cross-sectional study between $1^{\text {st }}$ January 2020 and 30 th January 2020 for all cases reported as suspected measles in the online measles surveillance database (e-measles and enotifikasi) between $1^{\text {st }}$ January 2015 to $31^{\text {st }}$ December 2019 in the district of Larut, Matang and Selama in Perak. Larut, Matang and Selama is one of the 11 districts in Perak with a land area of $2046.578 \mathrm{~km}^{2}{ }^{19}$. The total population in 2016 was $356200^{20}$.

In Malaysia, all cases suspected of measles in healthcare facilities either in the government or private are required by the law to be reported ${ }^{21}$. Both e-notifikasi and e-measles are developed and run by the Ministry of Health Malaysia. E-notifikasi is an online notification system which is used by healthcare facilities to notify all notifiable disease to the district health office ${ }^{22}$. E-measles was developed to standardised the reporting, investigation and findings at the district, state and national level for the control and prevention of measles. All cases of measles received by the health inspector at the district health office from e-notifikasi are investigated within 48 hours from the notification. The investigation is done using an investigation form which includes details of the patients (age, sex, date onset of rashes, date of the specimen), past medical history of the case (immunisation history, measles immunisation status, number of doses and last measles dose date) and the measles coverage area in the locality. All this data is then entered into the emeasles.

Following WHO recommendations, laboratory confirmation of measles was based on detection of anti-measles virus IgM antibodies by enzymelinked immunosorbent assay (ELISA) or the detection of measles virus RNA by reverse transcriptase-polymerase chain reaction (RT-PCR) in throat swabs, oral fluid or nasopharyngeal mucous or urine ${ }^{23}$. All the laboratory specimen for this study was sent to the National Public Health Laboratory which is a WHO reference laboratory for measles ${ }^{24}$. We included all the reported cases of measles to the Larut, Matang and Selama health district office between $1^{\text {st }}$ January 2015 to $31^{\text {st }}$ December 2019. Reported cases without laboratory or confirmatory test for measles were excluded.

Ethical approval for this study was obtained from the Medical Research and Ethics Committee (MREC), Ministry of Health Malaysia.

\section{Data Collection and Analysis}

Data collection and analysis was conducted at the Larut, Matang and Selama Health District. Data was downloaded from e-measles. This was followed by importing the data and analysing of the data by using IBM Statistical Package for Social Science (SPSS) version 24.0.

\section{i)To determine the incidence rate}

The incidence rate for suspected and confirmed measles cases for the year 2015, 2016, 2017, 2018 and 2019 was calculated by using the following formula:

For suspected measles(per 100,000 population): Number of reported suspected measles in the Larut.

Matang and Selama Health

district for the respective year $x 100,000$

Estimated number of population in

Larut Matang and Selama in the year

For confirmed measles(per $1,000,000$ population): Number of laboratory-confirmed measles in the Larut.

Matang and Selama Health

district for the respective year $\quad \times 1,000,000$

Estimated number of population in

Larut Matang and Selama in the year

Suspected measles was defined as any person diagnosed as measles by a clinician and notified to the district health office. Confirmed measles was defined as laboratory-confirmed cases. Estimated population in Larut, Matang and Selama for the year 2015 to 2019 was obtained from the record of population projection from the Department of Statistics, Malaysia.

ii)To determine the sensitivity, specificity, positive predictive value and negative predictive value of the clinical case definitions 
We used the clinical case definition of measles as a case with fever and maculopapular rash and at least of one of the ' $3 \mathrm{Cs}$ ' (cough, coryza and conjunctivitis) as advised by disease control division, Ministry of Health Malaysia ${ }^{16}$. Any of the reported suspected measles cases by the physician that fulfil this definition were considered as meeting the clinical case definition. Any cases reported as suspected measles but do not fulfil this case definition were considered otherwise.

We then evaluated the performance of the clinical case definition in detecting laboratory confirmed measles cases. This was achieved by measuring the sensitivity, specificity and the positive predictive values (PPV) and negative predictive values (NPV) of the clinical case definitions compared to laboratory confirmation. Sensitivity was defined as the proportion of all cases of measles that were serologically confirmed that met the clinical case definition ( true positive rate). Sensitivity was computed by dividing the number of serologically confirmed cases that fulfil the clinical case definition (a) by all serologically confirmed cases $(a+c)($ Table 2$)$.

Specificity was the proportion of not serologically confirmed cases (negative results of serological testing) that did not meet the clinical case definitions (true negative rate). It was computed by dividing the number of cases that did not meet the case definition and negative serological test (d) by all of the serologically negative cases $(b+d)$ (Table 2).

PPV was the proportion of the cases that fulfilled the case definition and had a positive serological result (i.e. the probability). It was computed by dividing the number of cases that met the case definition (a) and were serologically confirmed by the total number of persons meeting the clinical case definition $(a+b)$ (Table 2). NPV was the proportion of cases that did not meet the clinical case definition that was not serologically confirmed. NPV was computed by dividing the cases that were not classified as clinical cases and not serologically confirmed (d) by all persons who did not have a clinical case $(\mathrm{c}+\mathrm{d})$ (Table 2$)$.

The 95\% confidence intervals for sensitivity, specificity, PPV and NPV were calculated using MedCalc ${ }^{25}$. The sample size was calculated for both sensitivity and specificity by using Pass Software ${ }^{26}$. The sensitivity and specificity were set at 0.88 and $0.48^{18}$. The prevalence of measles was set at 0.1 from all the reported measle cases. The required sample size obtained was 310 cases. Therefore, we included all the cases from the year 2015 to 2019 which was 312 cases.

\section{RESULTS}

\section{Characteristics of the reported cases}

Between $1^{\text {st }}$ January 2015 and $31^{\text {st }}$ December 2019, a total of 359 cases of suspected measles were reported in Larut, Matang and Selama. Forty-seven $(14.7 \%)$ of the cases were discarded as no laboratory test was performed. Table 1 shows the characteristics of the remaining 312 suspected cases. All the reported cases presented with maculopapular rash and history of fever, 133 cases $(42.9 \%)$ had a cough, 111 cases $(34.7 \%)$ had coryza and 12 cases $(3.8 \%)$ had conjunctivitis. All the cases were Malaysian except for 3 cases (2 Chinese and 1 Vietnamese). There was no measles death reported in Larut Matang and Selama district during the period. The only known complication was diarrhoea (4 cases). During the 5 years, there was 3 measles outbreak in the district. All occurred in the year 2017 involving a total of 7 confirmed cases.

From 312 suspected cases, 30 cases were confirmed measles by laboratory investigation. Majority of the cases were less than 1 year old (56.7\%). Followed by more than 15 years old age group $(26.7 \%)$ and the age group between 1 to 5 years old $(16.7 \%)$. All confirmed cases were Malaysian citizens from Malay ethnicity with male cases being slightly more than female cases (17 vs 13). All of them had a maculopapular rash and a history of fever. Cough, coryza or conjunctivitis (meet the clinical case definition) was reported by $17(56.7 \%)$ of them. From the 30 cases, 10 (33.3\%) had a history of measles vaccination, 8 (26.7\%) were not vaccinated and $2(6.7 \%)$ with unknown vaccination status. Ten cases (33.3\%) were not qualified for measles vaccination as yet according to Malaysia National Immunisation Programme. Only 1 case (3.3\%) had documented 2 doses of measles vaccination, 8 cases $(26.7 \%)$ had 1 dose of measles vaccination, 18 cases $(60.0 \%)$ had not received any and 3 cases $(10.0 \%)$ of an unknown number of measles vaccination dose received.

The incidence rate for suspected measles and confirmed measles

Figure 1 shows the incidence rate of reported suspected measles cases per 100,000 population yearly between 2015 to 2019 in the Larut, Matang and Selama District. The incidence rate of confirmed measles cases per million population from the year 2015 to 2019 is shown in Figure 2.

\section{Evaluation of the measles clinical case definition}

Table 2 shows the sensitivity, specificity, positive predictive value (PPV) and negative predictive value (NPV) of measles clinical case definition in Larut, Matang and Selama between the year 2015 and 2019. The sensitivity of the clinical case definition in confirming measles was $86.67 \%$ (95\% $\mathrm{Cl}: 69.28 \%$, 96.24\%), specificity $47.52 \%(95 \% \mathrm{Cl}$ : 41.56\%, 53.52\%) . PPV $14.95 \%$ (95\% Cl $12.81 \%$, $17.36 \%)$, NPV $97.10 \%$ (93.03\%, 98.83\%). 
Table 1: Characteristics of the reported measles cases in Larut, Matang and Selama District Health Office from $1^{\text {st }}$ January 2015 to $31^{\text {st }}$ December $2019(n=312)$

\begin{tabular}{|c|c|}
\hline Variable & n (\%) \\
\hline \multicolumn{2}{|l|}{ Socio-demographic } \\
\hline$<1$ year & 149 (47.8\%) \\
\hline $1-5$ years & $98(31.4 \%)$ \\
\hline $6-14$ years & $33(10.6 \%)$ \\
\hline$>15$ years & 32 (10.2\%) \\
\hline \multicolumn{2}{|l|}{ Gender } \\
\hline Male & $163(52.2 \%)$ \\
\hline Female & $149(47.8 \%)$ \\
\hline \multicolumn{2}{|l|}{ Ethnicity } \\
\hline Malay & $281(90.1 \%)$ \\
\hline Chinese & $23(7.4 \%)$ \\
\hline Indian & $5(1.5 \%)$ \\
\hline Others & $3(1.0 \%)$ \\
\hline \multicolumn{2}{|l|}{ Fulfil clinical case definition ${ }^{b}$} \\
\hline Yes & $174(55.8 \%)$ \\
\hline No & 138 (44.2\%) \\
\hline \multicolumn{2}{|l|}{ Immunization } \\
\hline \multicolumn{2}{|l|}{ Received measles immunization } \\
\hline Yes & 162 (51.9\%) \\
\hline No & 139 (44.6\%) \\
\hline Not known & $11(3.5 \%)$ \\
\hline \multicolumn{2}{|l|}{ Dose received } \\
\hline 0 & 139 (46.6\%) \\
\hline 1 & 67 (20.6\%) \\
\hline 2 & 27 (8.4\%) \\
\hline Not known & $79(24.4 \%)$ \\
\hline \multicolumn{2}{|l|}{ Healthcare } \\
\hline Distance from house to healthcare (km) & $4.4(2.18)^{a}$ \\
\hline
\end{tabular}

amean(standard deviation)

${ }^{b}$ clinical case definition is defined as any person with fever and maculopapular rash and present of 1 of the following: cough or coryza or conjunctivitis

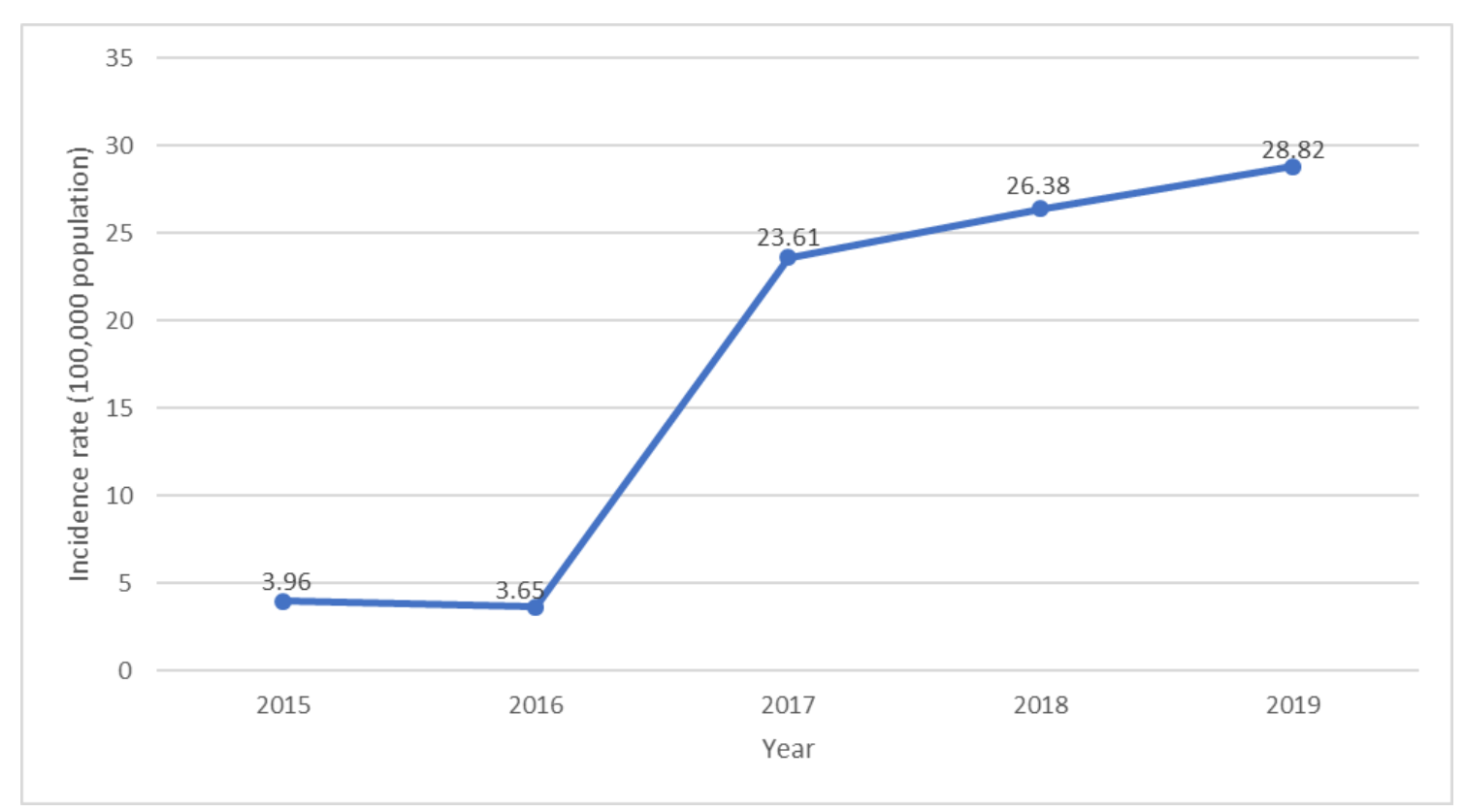

Figure 1: Incidence rate of reported suspected measles cases reported to Larut, Matang and Selama Health District Office between the year 2015 to 2019 


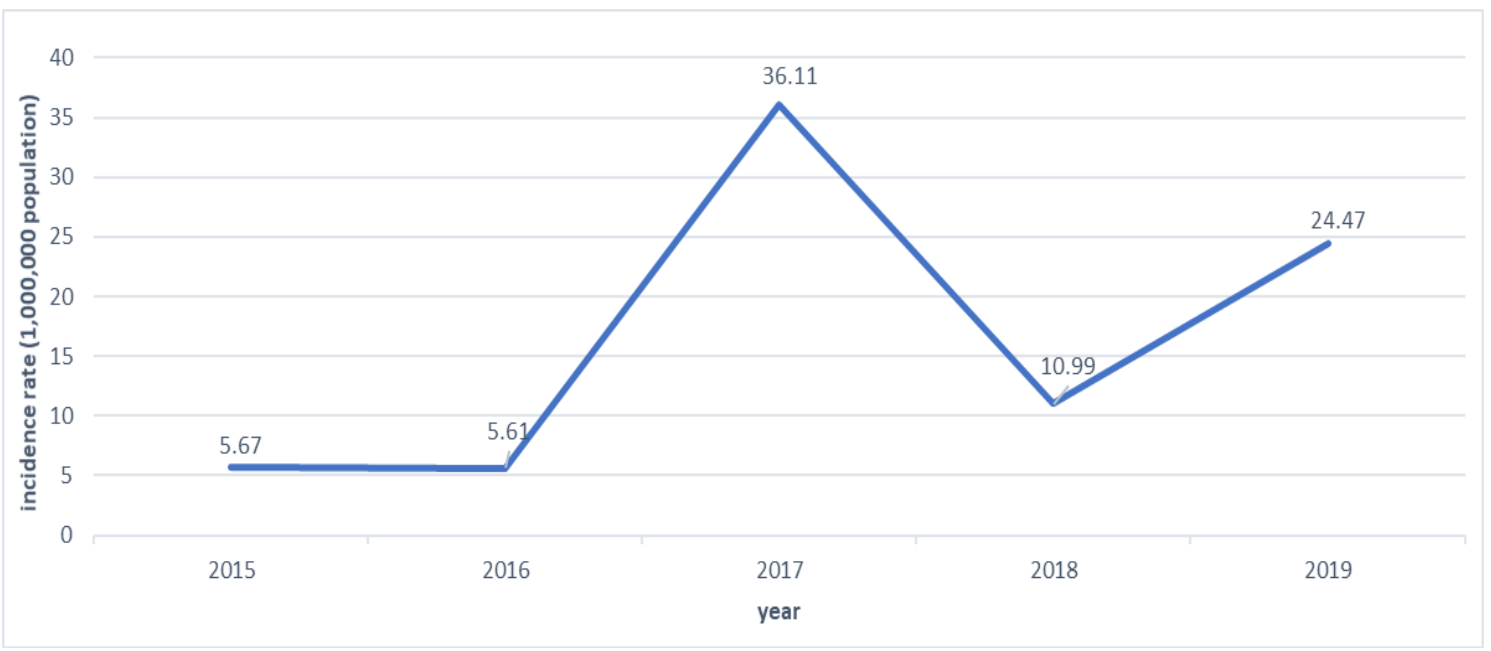

Figure 2: Incidence rate of confirmed measles cases in Larut, Matang and Selama district between the year 2015 to 2019

Table 2: Sensitivity, specificity, positive predictive value and negative predictive value of measles clinical case definition in Larut, Matang and Selama District

\begin{tabular}{lllll}
\hline & & Measles IgM Antibody Positive & Measles IgM Antibody Negative & Total \\
\hline $\begin{array}{llll}\text { Clinical case } \\
\text { definition }\end{array}$ & Yes & 26 & 148 & 174 \\
fulfilled $^{\mathrm{a}}$ & & $(\mathrm{a})$ & $(\mathrm{b})$ & $(\mathrm{a}+\mathrm{b})$ \\
& No & 4 & 134 & 138 \\
& & $(\mathrm{c})$ & $(\mathrm{d})$ & $(\mathrm{c}+\mathrm{d})$ \\
& Total & 30 & 282 & 312 \\
\hline
\end{tabular}

${ }^{a}$ clinical case definition is defined as any person with fever and maculopapular rash and present of 1 of the following: cough or coryza or conjunctivitis

\section{DISCUSSION}

\section{Characteristics of the cases}

Most of the suspected and confirmed measle cases were among less than 1 -year-old followed by the 1 to 5 years old age group. Historically infants were believed to be less affected by measles, however, this may no longer be true ${ }^{27}$. Of the 17 confirmed cases less than 1 -year-old, 4 cases were below the age of 9 months old. Therefore, not qualified for the first dose of MCV vaccination in Malaysia. 13 of the other cases were at or above the age for the first dose of MCV vaccinations. It has long been believed that infants less than 1year-old were protected by the anti-measles antibody transmitted from their mothers during the pregnancy which lasted until the end of their first year ${ }^{28}$. However, this was shown to be partly wrong with documented cases of measles occurring in cases in infants less than 1-year-old and sometimes younger than 6 months ${ }^{29}$.

A systematic review of studies on measles maternal antibody in infants in measles elimination settings reported despite about $80 \%$ to $100 \%$ of infants were protected from measles at birth, there is limited protection in infants more than 4 months old ${ }^{30}$. In Malaysia, the first dose of $M C V$ is given at 9 months as recommended by WHO. Hence, the questions if WHO should recommend and Malaysia should implement earlier age for the first dose of MCV vaccination. If the first dose is administered too early, the immune response can be blunted due to immunologic immaturity and interference of the maternal antibody ${ }^{31}$. Vaccination before the age of 6 months often fails to induce seroconversion due to the immaturity of the infant's immune system as well as the presence of neutralizing maternal antibodies ${ }^{32}$. Even at the age of 9 months, primary vaccination failures could occur in up to $10 \%$ to $15 \%$ of the infants ${ }^{33}$. Therefore, the recommended age for vaccination must be balanced between the risk of primary vaccine failure which decreases with increasing age, with the risk of measles virus infection occurring before vaccination which increases with ages.

WHO currently recommends two doses of MCV vaccination. Studies have shown in children who did not respond to the first dose of measles vaccine, almost $95 \%$ developed protective 
immunity after the second dose ${ }^{34}$. This is further echoed by WHO position paper on Measles Vaccine, which advises MCV1 vaccination for countries with ongoing transmission of measles should be at 9 months of age with MCV2 dose should be administered with a minimum interval between MCV1 and MCV2 of 4 weeks $^{34}$. However, WHO advises a supplementary dose of MCV should be given to infants from 6 months of age in the following situations: 1) during a measles outbreak as part of intensified service delivery; 2) during campaigns in settings where the risk of measles among infants $<9$ months of age remains high 3 ) internally displaced populations and refugees and populations in conflict zones; 4 ) individual infants at high risk of contracting measles; 5) infants travelling to countries experiencing measles outbreaks and 6) infants known to be HIV infected or exposed (born to an HIV-infected woman).

There were slightly more male than female in the confirmed cases (17 vs 13 ). This is most likely due to the higher number of reported suspected measles cases among male compared to female. An analysis using chi-square analysis found there is no significant difference among gender $(p=0.610)$.

Malay ethnicity was reported as the highest number of suspected measles cases. Therefore, unsurprisingly, all the confirmed measles cases were from this ethnicity. Although Malay is the major ethnic group in Larut Matang and Selama at almost $65 \%$ of the population ${ }^{20}$, this does not explain the disproportionate incidence rate among the ethnic group. Record of refused vaccination kept at the district level from 2015 to 2019 showed a total of 212 children were not vaccinated for MMR due to parents refusal. All of the documented refusals were among Malay ethnicity. Most of the cases were close to health facilities with the mean distance to the nearest healthcare facilities was less than $5 \mathrm{~km}$. A study has shown that distance more than $20 \mathrm{~km}$ greatly affect the prognosis of measles cases ${ }^{35}$.

\section{The incidence rate for reported and confirmed measles}

In 2016, there was a slight notch in the incidence rate of suspected measles cases in the district. Followed by increasing in the trend of suspected measles cases every year. Almost 8 fold increase in the incidence rate in 2017 was seen as compared to 2016 and the suspected measles incidence rate was at an all-time high at 28.82 per 100,000 population in 2019 . Compared to the incidence rate of suspected measles for the Perak state itself, a similar trend is observed with the incidence rate took a slight dip in 2016 from 7.63 to 7.16 per 100,000 population and then showed an increasing trend but not as drastically as seen in Larut Matang and Selama to 16.68 in 2017, 24.36 in 2018 and 19.62 per 100,000 population in 2019.
For the laboratory-confirmed measles cases, the trend showed a similar slight decline in 2016, followed by drastic increases in 2017. Most likely the increase in both the suspected and confirmed measles in 2017 occurred as a result of 3 outbreaks occurred in Larut Matang and Selama Health district in the year. All the 3 outbreaks occurred in June involving 3 cases, 2 cases and 3 cases. Epidemiological investigation revealed all three outbreaks had an epidemiological link with cases from outside the state which could have been the source of infection. Outbreaks were also reported in other parts of Perak leading to the increased in both reported and suspected measles incidence rate for Perak state as well.

The relatively low incidence rate of both reported and suspected measles before 2017 in the district of Larut, Matang and Selama could also be due to under-reporting of cases. Therefore, it might not reflect the true burden of the disease. Studies have shown that physicians tend to underdiagnosing and under-reporting mandatory reporting diseases when considered not severe ${ }^{36,37}$. The 2017 outbreaks increased physicians awareness and lead to physicians having a higher index of suspicion for measles, increased notification of suspected measles cases despite the incidence rate in 2018 and 2019 for confirmed measles showed a decline ${ }^{38}$.

\section{Evaluation of the measles clinical case definition}

In the study duration, only $55.8 \%$ of the cases reported as suspected measles fulfilled the clinical case definition as compared to $86.7 \%$ of the confirmed measle cases. In our sample, the clinical case definition has low PPV. PPV is the proportion of people that fulfilled the clinical case definition and have measles ${ }^{39}$. Studies have shown that PPV is influenced by the incidence rate of measles ${ }^{40}$. A review on four studies conducted on measles reported that for a population with an incidence rate of measles between 10 to 30 per million population, the PPV is estimated to be around $10 \%{ }^{18}$. This finding is in keeping with our study.

Despite the measles incidence in our population showed increasing in trend, the overall PPV was still low as the incidence is still relatively low compared to Africa (incident rate of 841 per million population $)^{41}$. In-country such as the United States where the reported measles incidence has been $<1$ case per 1 million population, the prediction of measles using the PPV is likely to be even closer to $0^{42}$. The low PPV of the measles clinical case definition indicates that most of the suspected measles cases were not true measles case. The low PPV also implies that serological confirmation of all measles cases in Larut, Matang and Selama is important to ensure an accurate diagnosis.

The clinical case definition had a high sensitivity of above $80 \%$. The high sensitivity meant that the 
proportion of the suspected measles cases which have measles will be detected by the clinical case definitions ${ }^{39}$. This is similar to the systematic review of the sensitivity of measles clinical case definition that reported sensitivity of $76 \%-88 \%{ }^{18}$. A study done in Brazil, evaluating the sensitivity of the clinical case definition in conforming measles reported an overall sensitivity of $100 \%{ }^{43}$. However, studies have shown that the sensitivity of the clinical case definition did not vary much with measles incidence ${ }^{18}$. The higher sensitivity seen in the Brazil study could have been due to the different populations and their sample population limited to patients presented at two primary health care unit and a general hospital. The incidence rate for measles in Rio De Janeiro in 2019 was almost similar to our incidence at 30 per million population ${ }^{44}$. The high sensitivity of the clinical case definition meant that it can accurately identify a high proportion of the cases which have measles.

The specificity of the clinical case definition was less than $48 \%$. Specificity refers to the proportion of the cases with confirmed negative measles and does not meet the clinical case definition ${ }^{39}$. Specificity is believed to be influenced by the incidence of measles ${ }^{18}$. Although sensitivity is not affected by the incidence of measles, specificity varies depending on the incidence of other exanthems that presented similar to measles and meet the clinical case definition ${ }^{18}$. For example, if other exanthems such as rubella meet the clinical case definition while the incidence of measles itself is low, the specificity of the clinical case definition will decrease as other exanthem increases in the population. In contrast, if rubella and other exanthem do not meet the clinical case definition, the specificity of the clinical case definition will increase with an increased incidence of measles.

The NPV of the clinical case definition was extremely high at $97.10 \%$. NPV is the proportion of reported measles that failed to meet the clinical case definition and later confirmed by the laboratory as not measles ${ }^{39}$. This means that cases that did not meet the clinical case definitions were most likely to be other illnesses. Therefore, based on the reported suspected measles cases between 2015 to 2019, almost all the cases that did not fulfil the case definition were unlikely to be measles. The high NPV of the clinical case definition is supported by a study evaluating the measles clinical case definition in New York City, CONCLUSION

From this study, both suspected and confirmed measles rate in the district generally showed increasing in trend. The effectiveness of the measles clinical case definition showed it has high sensitivity and NPV but lower specificity and PPV. that reported the NPV value of the clinical case definition almost similar to ours at $98 \%{ }^{18}$.

Since the study population consisted of the population in Larut, Matang and Selama District, the result cannot be generalized to other population. We had no access to external information other than the online notification database. Therefore, the incidence of suspected and confirmed measles depended on the notification by physicians. For the calculation of the population in Larut, Matang and Selama from 2015 and 2019, we used the projected population provided by the local department of statistics. This is not the true population but rather an estimation. The predictive values are determined by the incidence of measles cases. Therefore, the predictive values will change with changing incidence rates.

The strength of this study was that the confirmatory test for measles was done on a single laboratory which a WHO recognised laboratory for measles, therefore reducing interlaboratory bias. We also used the two online databases for measles surveillance in Malaysia. About $87 \%$ of the suspected cases in the online databases during the study duration were laboratory confirmation cases, which is above the WHO recommended standard $\geq 80 \%^{34}$.

While the sensitivity and specificity can be used to 'rule out' or 'rule in' measles, but they have limited usefulness as it cannot be used to estimate the probability of a disease in a patient. The almost $100 \%$ NPV of the clinical case definition meant that any cases that do not meet the clinical case definition are almost unlikely to have confirmed measles. On the other hand, the low PPV of the clinical case meant that in our population only about $15 \%$ of the cases that met the clinical case definition are likely to have measles. To ensure that all suspected measles are truly measles cases, clinical diagnosis of measles alone without serological confirmation is not enough. A laboratory testing of suspected cases for confirmation is critical to identify true cases. This is to guide public health action. As Malaysia progress towards Measles elimination, the public health system responds vigorously to measles cases and initiates outbreak control in the community. Misidentification of measles cases results in the misdirection of the outbreak response, which may be initiated when not needed or not initiated when needed.

The findings suggest that a case that does not meet the clinical case definition are unlikely to be measles. For cases that do meet the clinical case definition, laboratory confirmation or epidemiological link to a confirmed case is critical to identify true cases and guide the public health action. 


\section{REFERENCES}

1. Bennett JE, Dolin R, Blaser MJ. Mandell, Douglas, and Bennett's : Principles and Practice of Infectious Diseases. Vol. 1. Elsevier Health Sciences 2014: 200-204.

2. World Health Organization. Immunization, Vaccines and Biologicals: Measles. January 2020 [cited 2020 February 06]. Available from: https://www.who.int/immunization/dise ases/measles/en/

3. Centers for Disease Control and Prevention. Measles (Rubeola), for Healthcare Professionals. 2018 February 5 [Cited 2020 February 06]; Section: [Clinical Features]. Available from: https://www.cdc.gov/measles/hcp/inde x.html

4. Samb B, Aaby P, Whittle H, et al. Decline in Measles Case Fatality Ratio after the Introduction of Measles Immunization in Rural Senegal. American Journal of Epidemiology. 1997;145(1):51-57. doi: 10.1093/oxfordjournals.aje.a009031.

5. Cairns KL, Nandy R, Grais RF. Challenges in Measuring Measles Case Fatality Ratios in Settings without Vital Registration. Emerging Themes in Epidemiology. 2010;7(1):4

6. Okamoto Y, Vricella LA, Moss WJ, et al. Immature CD4+ CD8+ Thymocytes are Preferentially Infected by Measles Virus in Human Thymic Organ Cultures. PloS One. 2012;7(9):e45999. doi.org/10.1371/journal.pone.0045999.

7. Rosen JB, Arciuolo RJ, Khawja AM, et al. Public Health Consequences of a 2013 Measles Outbreak in New York City. JAMA Pediatrics. 2018;172(9):811-817.

8. Perry RT, Gacic-Dobo M, Dabbagh A, et al. Progress Toward Regional Measles Elimination-Worldwide, 2000-2013. MMWR Morbidity and Mortality Weekly Report. 2014;63(45):1034.

9. Cheong AT, Tong SF, Khoo EM. How Useful is a History of Rubella Vaccination for Determination of Disease Susceptibility? A Cross-Sectional Study at a Public Funded Health Clinic in Malaysia. BMC Family Practice. 2013;14(1):19. doi.org/10.1186/1471-2296-14-1.

10. Saraswathy $T$, Zahrin $H N$, Norhashmimi $H$, et al. Impact of a Measles Elimination Strategy on Measles Incidence in Malaysia.
Southeast Asian J Trop Med Public Health. 2009;40(4):742.

11. Sniadack DH, Mendoza-Aldana J, Jee $Y$, et al. Progress and Challenges for Measles Elimination by 2012 in the Western Pacific Region. The Journal of Infectious Diseases. 2011;204(suppl_1):S439-S446.

12. Hagan JE, Kriss JL, Takashima Y, et al. Progress Toward Measles EliminationWestern Pacific Region, 2013-2017. Morbidity and Mortality Weekly Report. 2018;67(17):491.

13. World Health Organization (Western Pacific Region). Measles-Rubella Bulletin. Manila: WHO. 2019; 13 (1): 1-10.

14. Abidin ZBZ. Factors Associated With Adherence Towards Different Vaccines OF Childhood Immunization of under Five Children among Mothers Attending Klinik Kesihatan Seremban [Master's Thesis]. Serdang (Selangor): Universiti Putra Malaysia; 2017.

15. World Health Organization. Eliminating measles and rubella and preventing congenital rubella infection: WHO European Region strategic plan 20052010. Denmark: WHO Regional Office Europe; 2005.

16. Ministry of Health Malaysia. Case Definitions for Infectious Diseases in Malaysia. $3^{\text {rd }}$ Edition. Putrajaya: Disease Control Division; 2017.

17. Nsubuga F, Ampaire I, Kasasa $S$, et al. Positive Predictive Value and Effectiveness of Measles Case-Based Surveillance in Uganda, 2012-2015. PLOS ONE. 2017;12(9):e0184549. doi: $10.1371 /$ journal.pone. 0184549 .

18. Hutchins SS, Papania MJ, Amler R, et al. Evaluation of the Measles Clinical Case Definition. The Journal of Infectious Diseases. 2004 May 1;189 Suppl 1:S153-9. doi: $10.1086 / 379652$.

19. Data.gov.my [internet]. Putrajaya: Jabatan Ukur dan Pemetaan Malaysia; [cited 2020 February 06]. Available from http://www.data.gov.my/data/ms_MY/d ataset/keluasanmalaysia/resource/f9c7dc6f-dd9d-4ea38eb3-f722e75d1de0

20. Kerajaan Negeri Perak. Basic Data Negeri Perak Darul Ridzuan 2016. Ipoh; Setiausaha Kerajaan Negeri Perak; 2016. 
21. Government of Malaysia. Undang-Undang Malaysia: Akta Pencegahan dan Kawalan Penyakit Berjangkit 1988 (Act 342). Kuala Lumpur, Malaysia; 1988.

22. Liyanatul Najwa Z, Nadiatul Ima Z, Wan $M$, et al. The Concept of District Health Management in Malaysia. International Journal of Public Health and Clinical Sciences 2016;3(1):1-16.

23. Schluter WW, Xiaojun W, Mendoza-Aldana $\mathrm{J}$, et al. Progress toward Measles Elimination-Western Pacific Region, 2009-2012. MMWR Morbidity and Mortality Weekly Report. 2013;62(22):443.

24. World Health Organization. Public health Laboratories for Alert and Response: a WHO Guidance Document. Manila: WHO Regional Office for the Western Pacific; 2012.

25. MEDCALC. Easy to use Statistical Software. Version 19.1.7. Ostend (Belgium): MedCalc Software Ltd; 2020.

26. Bujang MA, Adnan TH. Requirements for Minimum Sample Size for Sensitivity and Specificity Analysis. Journal of Clinical Diagnostic Res. 2016;10(10):YE01-YE06.

27. Muscat MJT. Who Gets Measles in Europe?. The Journal of Infectious Diseases. 2011;204(suppl_1):S353-S365.

28. Principi N, Esposito S. Early Vaccination: a Provisional Measure to Prevent Measles in Infants. The Lancet Infectious Diseases. 2019;19(11):1157-1158. doi: $10.1016 / \mathrm{s} 1473-3099(19) 30520-1$.

29. European Centre for Disease Prevention and Control. Surveillance Report: measles and Rubella Surveillance 2017. Stockholm: European Centre for Disease Prevention and Control; 2018.

30. Guerra FM, Crowcroft NS, Friedman L, et al. Waning of Measles Maternal Antibody in Infants in Measles Elimination SettingsA Systematic Literature Review. Vaccine. 2018;36(10):1248-1255.

31. Hughes SL, Bolotin S, Khan S, et al. The Effect of Time since Measles Vaccination and Age at First Dose on Measles Vaccine Effectiveness-A Systematic Review. Vaccine. 2020; 38 (3):460-469.

32. Cáceres VM, Strebel PM, Sutter RW. Factors Determining Prevalence of Maternal Antibody to Measles Virus
Throughout Infancy: A Review. Clinical Infectious Diseases. 2000;31(1):110-119.

33. Orenstein WA, Cairns L, Hinman A, et al. Measles and Rubella Global Strategic Plan 2012-2020 Midterm Review Report: Background and Summary. Vaccine. 2018;36:A35-A42.

34. World Health Organization. Measles vaccines: WHO position paper, April 2017Recommendations. 2019;37(2):219-222.

35. Poletti P, Parlamento S, Fayyisaa T, et al. The Hidden Burden of Measles in Ethiopia: How Distance to Hospital Shapes the Disease Mortality Rate. BMC Medicine. 2018;16(1). doi: 10.1186/s12916-0181171-y.

36. Figueiras $A$, Lado $E$, Fernández $S$, et al. Influence of Physicians' Attitudes on Under-Notifying Infectious Diseases: A Longitudinal Study. Public Health. 2004;118(7):521-526. doi: 10.1016/j.puhe.2003.12.015.

37. Mansuri FA, Kalar M. Factors Responsible for Under Reporting of Notifiable Infectious Diseases by General Practitioners: A Veiled Reality. Biomedica. 2014;30(2):126-129.

38. Bernard H, Werber D, Höhle M. Estimating the Under-Reporting of Norovirus Illness in Germany Utilizing Enhanced Awareness of Diarrhoea During a Large Outbreak of Shiga Toxin-Producing E. coli 0104: H4 in 2011-A Time Series Analysis. BMC infectious diseases. 2014;14(1):116.

39. Akobeng AK. Understanding diagnostic tests: Sensitivity, Specificity and Predictive Values. Acta Paediatrica. 2007;96(3):338-341. doi: 10.1111/j.16512227.2006.00180.x.

40. Romaguera RA, German RR, Klaucke DJP, et al. Evaluating Public Health Surveillance. Principles and Practise of Public Health Surveillance. 2000;2:17693.

41. Dabbagh A, Patel MK, Dumolard L, et al. Progress Toward Regional Measles Elimination-Worldwide, 2000-2016. MMWR Morbidity and Mortality Weekly Report. 2017;66(42):1148.

42. Clemmons NS, Wallace GS, Patel M, et al. Incidence of Measles in the United States, 2001-2015. JAMA. 2017;318(13):12791281. 
43. liveira SAD, Camacho LAB, Pereira ACDM, et al. Assessment of the Performance of a Definition of a Suspected Measles Case: Implications for Measles Surveillance. Revista Panamericana de Salud Pública. 2006;19(4):229-235. doi: 10.1590/s102049892006000400002 .

44. World Health Organization. Epidemiological Update Measles:
Situation Summary. Washington: Pan American Health Organization; 2019. 